\title{
A Remote Engineering Lab Based on Augmented Reality for Teaching Electronics
}

\author{
http://dx.doi.org/10.3991/ijoe.v9iS5.2496 \\ Salaheddin Odeh ${ }^{1}$, Shatha Abu Shanab ${ }^{2}$, Mahasen Anabtawi ${ }^{1}$, Rami Hodrob ${ }^{3}$ \\ ${ }^{1}$ Al-Quds University, Abu Dies, Jerusalem, Palestine. \\ ${ }^{2}$ Palestine Technical University-Kadoori, Tulkarm, Palestine. \\ ${ }^{3}$ Arab American University, Jenin, Palestine
}

\begin{abstract}
Many engineering students graduate with insufficient practical experience in many fields although their theoretical knowledge might be deep. One main reason is the lack of available labs. Unfortunately, other solutions such as virtual and remote labs presented by pure graphical visualization for assisting the students to develop their practical skills, cannot completely replace hand-on labs, because they lack reality and try to visualize instruments and experiments graphically. Our research is aimed at checking and proofing the appropriateness of augmented reality (AR) to be used in representing client user-interfaces in remote labs. Students can carry out an engineering experiment represented by real and virtual elements, components and equipment overlaid with virtual objects.
\end{abstract}

Index Terms-augmented reality; remote labs; instrumentation, comparative evaluation; image processing.

\section{INTRODUCTION}

Engineering is different from other pure sciences because of its applicable perspective. Engineering serves humanity by designing and creating new products for the service and welfare of human being. This is only possible after training engineering-students sufficient practical experimental work during study years at universities. Labs make science come alive because of two reasons [1]. First, labs represent the heart and soul of engineering learning. Second, they supply students with better understanding of theories. It has long been known that many labs present a well-established basis for future employment [2]. Most future works of engineering students will be in practical fields, which demands from them more time and efforts in labs. After graduation, they will not only depend on their theories acquired during their study at the university, but also on their practical knowledge they acquired by engineering labs. Unfortunately, labs are available only for a limited time for that huge number of students.

Through the educational goals proposed by ABET, it is evident that labs play a central role in illustrating concepts and principles, providing the ability to design and investigate, promoting social skills and improving technical skills. ABET is a nonprofit, non-governmental organization that accredits college and university programs in the disciplines of applied science, computing, engineering, and engineering technology [3]. Engineering students must have better understanding of the instructed theory; therefore most courses in engineering education require labs [4], [5]. There are three different categories of labs: hands-on labs, simulated labs and remote labs.
In hands-on labs, all equipment required to perform the experiment is physically set up, and the students performing the experiment are physically present in the lab. Those are the most popular type, they satisfy all goals previously stated by ABET, yet they are costly, put a high demand on space, instructor time and experimental infrastructure. However, Colwell et al. [6] emphasize that some of those labs can't meet special needs of disabled students.

Simulated labs are imitations of real experiments on computers, meaning instead of performing the experiment on actual equipment, the tests, and possibly even the data, are simulated on a computer [5]. Simulated labs have several drawbacks: they require large amount of time and effort to be developed, they may fail to faithfully model reality [7], they don't necessarily reduce cost [8], they often result in a disconnection between real and virtual worlds [9], and they rarely satisfy social skills of students.

Remote labs enabling students to carry out an experiment remotely through the Internet are mediated completely via a computer that can be considered as mediated reality. They require space and equipment but there is a distance between the students and the experiment; students are allowed to connect remotely and to control lab's equipment, using cameras to visualize experimenting results. A remote lab provides access to expensive and scarce equipment, enables sharing of devices with a pool of universities and thus increases the number of times and places for the students performing experiments [10], [11]. The emphasis of these systems on conceptual understanding often comes at the cost of degrading the student design skills [12]. This consideration was one of the primary motivations in building the remote AR lab [5], [13].

As stated early, engineering students graduate with insufficient practical experience in many fields although their theoretical knowledge might be deep. One main reason is the lack of available labs. Unfortunately, other solutions such as virtual and remote labs for assisting the students to develop their practical skills, cannot completely replace hand-on labs, because they lack reality and try to visualize instruments and experiments graphically. In virtual reality, experiments' data are obtained from theoretical calculation based on mathematical model, missing of instrumental errors, which weakens students' reference to reality, and thus, they can't later deal with these components and instruments in real work [13], [14]. In this investigation, a new emerging technology called augmented reality (AR), which combines the interactive real world with a generated one by an interactive computer system in such a way that they appear as one environment, tries to 
bypass the previously mentioned problems through providing students with AR labs as a combination of "real" labs augmented by virtual objects [15].

Our remote AR lab as it is the case with other Internetbased labs is available for students independent of time and place, and can be seen as practical feature of elearning. The kit of the remote AR lab is transmitted through a camera from lab to computer screen of student, where the student does his experiment. The kit holds all required real electrical and electronic components. A student can set up his experiment through selecting and wiring the components from his computer through a userinterface using augmented reality technology. Then, the client sends the acquired information to the lab server, which validates the correctness of these connections in order to avoid damaging the equipment of the lab; after that the lab server connects the corresponding switches of the experiment circuit. Real data can be obtained from the screen of instruments through a transferred live video.

As obvious, this research is aimed at replicating handon labs as much as possible in order to overwhelm the lack in virtual and remote labs in reproducing reality to be more effective in assisting students to develop their skills. In order to achieve this goal, we had to implement a novel system aimed at improving performing remote lab experiments through Internet using augmented reality technique. After having designed and implemented a prototype of the distributed remote AR lab, an evaluation to compare carrying out engineering experiments through our developed remote AR lab with conventional and virtual ones had been done.

By developing and implementing a remote augmented reality lab, the following objectives and goals will be achieved:

- Reproducing hand-on labs (experiment and instruments) as much as possible to allow students to move seamlessly from AR representations of test equipment in a remote lab environment to actual test equipment in a real lab.

- Students can access the lab from any PC's connected to the Internet and at any time.

- Students perform on real experiments remotely. Then, results of an experiment will be online visualized imitating hand-on lab.

- Students do their experiment with no fear of dealing with the instruments and components by hand.

- The components or expensive instruments are protected from damage through introducing an einstructor, which is available to prevent connection mistakes.

\section{AUGMENTED REALITY, VIRTUAL REALITY AND COMPUTER VISION}

Augmented reality (AR) system is progressing more and more with developing technology. Augmentation can be made with various different techniques in order to enhance the users surrounding environment in real-time. At present, applications of AR can be found in many areas and fields in our life. In this section, an overview is given about the basic definitions of AR, the major concepts of this technology, and a listing of some applications of AR. According to Sairio [6] and Silva et al. [7], augmented reality is defined as the combination of real environment

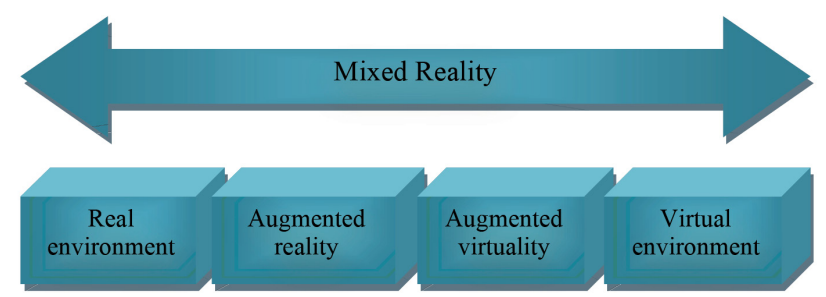

Figure 1. The Virtual-Reality Continuum [16].

with virtual computerized objects that can be in forms of text, 2D images, or 3D models, and/or enhancement to sound, graphics or other human senses. The appearance of a user in this ultimate system samples as he is working in a single real environment. Figure 1 presents a simplification of the virtual-reality continuum VRC [16] in which the real world and the virtual environment are at the two opposite ends of this continuum with the middle region called mixed reality (MR).

The time and motion in virtual reality is not predetermined as in computer animation. It provides more chances to users to act as if they are in the physical world, making the user to obtain more accurate mental sense of visualized space. In a virtual reality (VR) environment, the user is completely immersed in, and able to interact with a totally virtual environment. Virtual environment is not only a copy of the abstracted properties from some environments independent whether this environment is really or fictional, it also holds physical laws governing space, time, mechanics, material properties, etc. On the contrary, in an AR system, a combined view which will be seen by the user as a real view overlaid with computer-generated virtual objects. These virtual objects augment the real environment with additional information. To preserve the user's immersion in the real world, an augmented reality system merges the virtual images with a view of the real scene to create the augmented display [16]. Before having started to apply augmented reality in remote labs, we considered other AR systems, where this technology is successfully realized such as process control [17], medical systems [18], military systems [19], entertainment [20], and, last but not least, manufacturing, maintenance and repair [21].

Immersion is one way that is used to evaluate the virtual reality and augmented reality system; that is, the role of AR in combining and extending real and virtual worlds. The term of immersion examines the strengths of real world and virtual world in the manufactured environment. Achieving a perfect immersion would eliminate the line between reality and VR. There are two types of immersion [22],[23], [24]: Physical and mental immersion. Physical immersion is achieved by presenting to users a world and synthetic stimuli to one or more of their senses based on participants' positions and in response to actions. Physical immersion is important element of an augmented reality and virtual reality system which distinguishes real from virtual objects. The components of physical immersion: perspectivedependent images to each eye, synchronized audio to ears, and haptic information to body. These qualities must be adjusted in response to the users' positions. For example, approaching targeted objects means the object must provide a greater sound, be bigger in size and so forth when proximal. On the contraray, mental immersion can be achieved by fixed image visualization media. Mental 
immersion is described as "a sense of presence" within an environment. It is not as quantitatively controlled as physical immersion. Additionally, it is often difficult to measure the degree of necessary immersion or even how it is to be attained. Mental presence is dictated by various factors under different environments. How much sensory immersion is essential to create mental immersion is another topic that is still under investigation. Factors which present together for creating a mental immersion:

- Personally meaningful world which covers the subject and presentation manner of content aimed to engage.

- Interactivity which presents content through computer where the user can control action.

- Resolution which includes a resolution of display modalities, spatial as amount of information in image, temporal (response to dynamic changes) as frame or sample rate.

The time and motion in virtual reality is not predetermined as in computer animation. It provides more chances to users to act as if they are in the physical world, making the user to obtain more accurate mental sense of visualized space.

Augmented Reality against Virtual Reality: AR environment and virtual reality (VR) environment have been defined as the opposite ends of a continuum which are referred to as (VRC). In the VR, the user is completely immersed in, and able to interact with a totally virtual environment. Virtual environment is just a copy of the properties (abstraction) from some environments, whether this environment is really or fictional. This VR environment holds physical laws normally governing space, time, mechanics, material properties, etc. In contrast, an AR system generates a combined view for the user. The user sees an image that is the combination of the real object and a computer-generated virtual object. The virtual object augments the real environment with additional information. An AR system augments the real world scene and attempts to preserve the user's sense of being in the real world. To preserve the user's immersion in the real world, an augmented reality system merges the virtual images with a view of the real scene to create the augmented display [25], [26], [27].

Computer Vision and Augmented Reality: Computer vision is a diverse and nearly new field of study. There are an abundance of methods for solving various computer vision tasks. As there is not standard formulation of computer vision problems, these methods solve a specific task and rarely are used for a wide range of applications. Augmented reality systems are using computer vision methods to assure an alignment between the real world and the virtual object since it depends on the accuracy of taken information from the pixels that improve its functionality in solving the problem of tracking the virtual objects over the real sense [27], [28].

\section{E-LEARNING AND ONLINE LEARNING}

The progression of e-learning initially began in the form of correspondence such as printed materials; after that through multimedia, then depending on information technology such as audio-video conferences and, nowadays, through the Internet [29], [30]. The development of e-learning and multimedia technologies is adding new ways for teaching and training, enabling the e-learning approach to occupy a larger part of academic learning methodologies [31]. It is undeniable that contemporary technologies have made central changes to the ways of education. A lot of technologies such as bandwidth, video Internet and voice technology have been improved, leading to increase the demand on e-learning. Nowadays, an ordinary person can access huge quantities of information and knowledge from any terminate computer [31].

E-Learning is delivered or enabled learning achieved by electronic technology. Electronic technologies cover the Internet, television, videotape, intelligent tutoring systems, and computer-based training. E-learning via electronic technology assists the education and training environment. E-learning is increasingly complex since new technologies continue improving [32]. The requirements for successful e-learning are: network security, suitable bandwidth, cheap and reliable access to the Internet [32]. The requirements of educational processes on information and communications technology make a decision whether the teaching activities must be based on asynchronous or synchronous learning [33]. To this end, the applications of elearning determine whether the content of e-learning is synchronous or asynchronous; the differences between the two technologies or their mixtures is shown in the following [34]:

- Synchronous models are a real-time communication that carries out actions at the same time such as instant messaging or chat rooms and audio/video conferencing. The advantage of synchronous models supports the social side of learning, but synchronous models are more costly and require more developed technology such as higher network speed, and more complex equipment as Web cameras. The synchronous models can be used when the students work remotely with the lab equipment. The Internet enables the students with remote access to control physical lab apparatus, using video stream in quasi real time that give students a sense of actual environment of the experiment [35].

- Asynchronous models enable the user accessing the information whenever needed at anytime and from anywhere, such as multimedia presentations, message boards, Web pages or online quizzes.

- Hybrid models are mixed from the previous two models for exciting possibilities for e-learning which encourage social learning.

Online learning, whose definition is synonymous with Web-based learning or Internet-based learning, includes animations, simulations, audio and video sequences, peer and expert discussion groups, online mentoring, links to material on a corporate intranet or the Web, and communications with corporate education records. It is obvious from the previous definition that online learning presents a subset of e-learning [29]. A lot of people believe that the e-learning and the online learning are the same and there is no difference in meaning. But every term has a particular identifier. E-Learning is derived from the words 'electronic learning' that contains all electronic media such as Internet, satellite broadcast, audio/video tape, interactive TV, and CD-ROM. At present, e-learning has a number of applications that can be easily seen in our life as computer-based learning, Web-based learning, virtual classrooms, and digital collaboration what makes e-learning to be considered as the whole category of technology-based learning [29]. 


\section{EDUCATIONAL ENGINEERING LABS}

The main purpose of engineering education is to prepare engineers who can deal with equipment and instruments. Since engineering is an applied science, its courses are containing the biggest part of lab studies. Therefore, labs are essential in scientific education. Nowadays, many types of labs appear beside hand-on labs in the form of software or both software and hardware. Labs are classified in the three categories hand-on labs, virtual labs and remote labs. Universities are trying to reduce or eliminate costs of maintaining expensive equipment in traditional labs.

Remote and virtual labs may be created as a way to share hand-on lab for improving requisite skills of future engineers and satisfy economic constraints [36]. In a hands-on lab, a real experiment is locally realized. Two characteristics differentiate hands-on from the other two labs [37]. First, the real equipment that is used in the lab is physically locally connected. Second, the students and the equipment must locally present in the same land of lab. Virtual labs enable the student to access the engineering applications easily at anytime and from any computer. Examples of these engineering applications are simulations, demonstrations, and exercises. Virtual labs are very essential for proving the theory by practicing mathematical models. A virtual lab is a software simulation, which is an imitation of a real experiment represented by a mathematical model. The entire infrastructure required for labs is not real but achieved through computer generated graphics [37]. Remote labs can be considered as a section of e-learning in actual scientific researches, such as online courses, virtual classrooms, educational intranets, self-training, e-projects and role playing. Remote labs benefit from contemporary e-learning and Internet technologies. Now, many academic institutions provide a variety of remote lab experimentations designated as Webbased labs or online labs; these labs support remotely controlled physical experiments. Remote labs differ from virtual labs in degree of accurate and reliable description of a real-world system. Every category of laboratories attempts to reach the reality, as shown in Figure 2. Details on hands-on, simulated, and remote labs can be found in $\mathrm{Ma}$ et al. [37].

\section{DISTRIBUTED SYSTEM ARCHITECTURE}

The remote AR lab composed of hardware and software components enables the students to interact with an experimental setup located in another geographical location through the Internet. Students utilize a communication network to perform a lab experiment, and interact with a Web page to access the lab from their houses independent of time and place. The remote AR lab architecture consisting of subsystems and components is shown in Figure 3. In the following, the major subsystems from which the whole is made are discussed.

Lab server It presents the middleware over the Internet between the clients (the students) and the remote experiment. The user interacts with the experiment through the AR user-interface implemented in forms of a Web application, serving as mediator between the student and the lab server. The lab server is the backbone of the AR e-learning environment to which the lab instrumentations and the experimenting kit are connected.

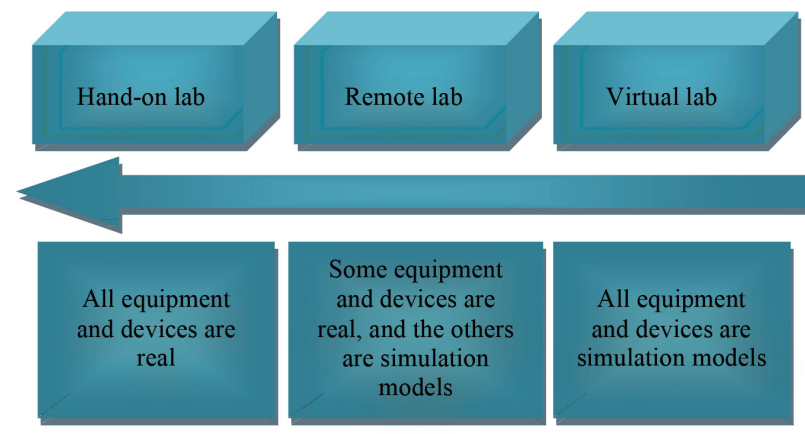

Figure 2. The realism of hand-on, remote and virtual lab.

Graphical user-interface It is of great significane to access the remote AR lab through a Web page over the Internet through a Web browser such as Microsoft Internet Explorer, Mozilla Firefox, Chrome etc. As such, a suitable mean for data exchange between the student and the lab server is provided. After activating the URL address of the Web page of the remote AR lab by the student, the Web browser loads the start Web page of the experiment lab, which embraces an authentication page for entering the system through a correct user name and password. Ergonomic aspects [38] are necessary for allowing effective human-computer interaction. The user-interface plays a central role for obtaining a harmonic interaction with the experimental setup. Various usability aspecst to enhance the intercation with user-interafce had been taken into account such as consistency of data display such as labeling and graphic conventions, efficient information assimilation by the user, minimal memory load on user, compatibility of data display with data entry, flexibility for user control of data display, presentation of information graphically where appropriate, standardized abbreviations, and presentation of digital values only where knowledge of numerical value is necessary and useful [39].

Video camera The video camera plays a central role in such kind of applications as the AR visualization depends on real-time video streams for approaching quasi real presentations. Therefore, a high quality Webcam is necessary to send real-time video of the experiment to give realistic feedback for the students.

Real experimental kit The represented AR circuit-board (kit) is built in such a way that the underlying image of the remote real kit is captured by a video camera and processed by a video server in real time that is finally augmented by graphical experiment elements. Circuit elements that are not on the video presentation of the kit can be graphically selected by means of a graphical component bar and can be then placed on the kit. In the bar, more than one resistor, capacitor, inductor, etc., are possible to be selected by the student, depending on his decisions or calculations required in the experiment. The lab server computes the final AR display consisting of computer graphics (virtual objects) and the video-presented kit in order to display it to the user. In this investigation, setting up computer graphics of electronic elements and equipment overlaid on real-time video of the experiment kit is what makes our distant learning environment augmentedrealistic, aiming at providing engineering students a quasi real environment lab.

E-Instructor Sensitive experiment elements such as ICs may be wrongly connected with the power supply, causing 


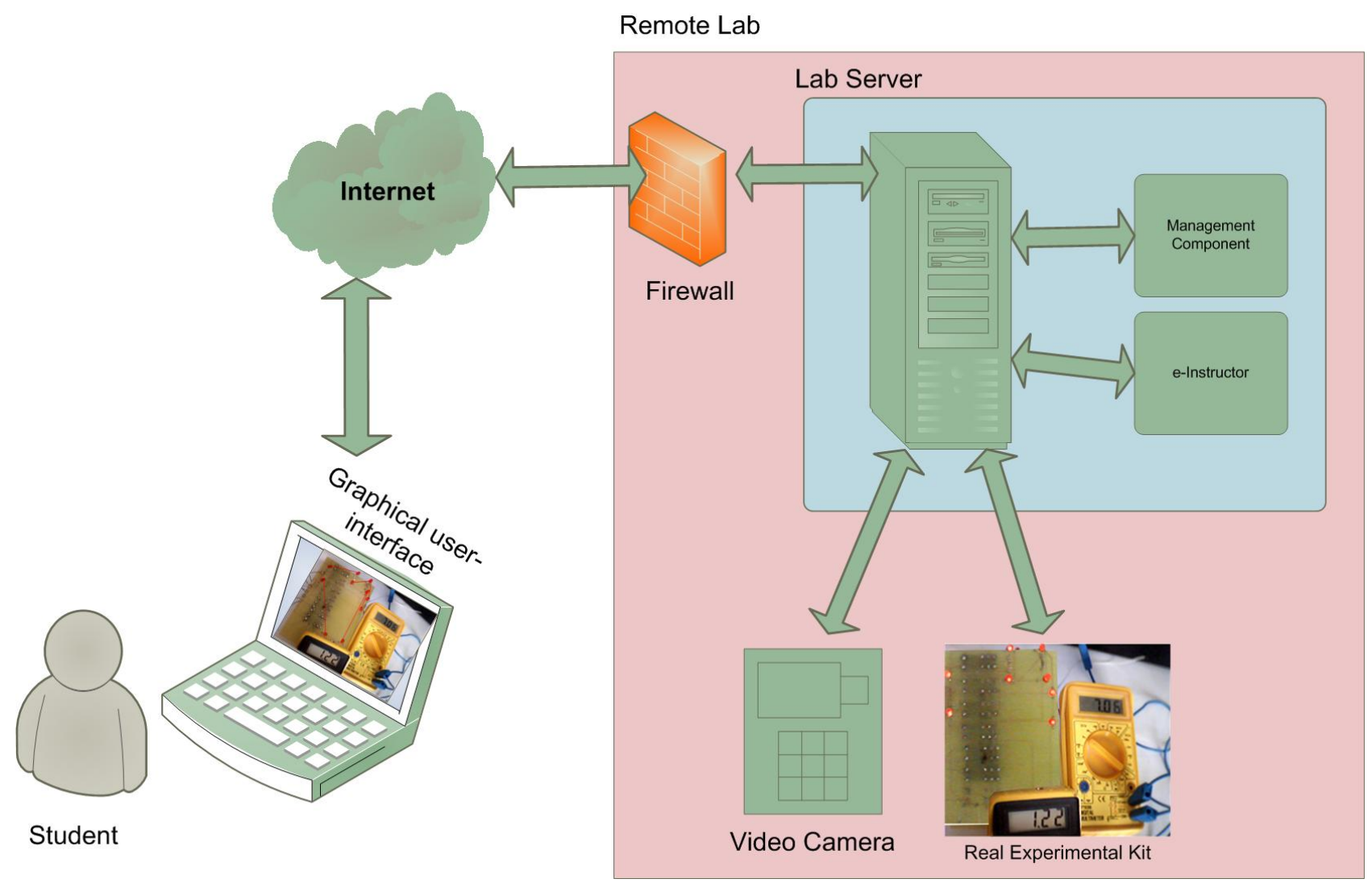

Figure 3. Distributed system architecture of the remote augmented reality

these components to get damaged. Therefore, we need a further software component for preventing such wrong configurations. Since this software component undertakes some activities of a human instructor, it is designated as einstructor. According to Hayes-Roth [40], rule-based systems automate problem-solving know-how and providing a means for capturing human expertise. The e-instructor is realized as a simplified rule-based system due to the fact that our focus is mainly on augmented reality and not on knowledge-based systems.

\section{IMPLEMENTATION}

The system components have been incrementally built within an iterative system and software engineering process. In the iterative process, the stages: specification, design, development, and testing are not chained, but rather interleaved and concurrent [41]. This section discusses some important hardware and software components of the remote AR lab.

Libraries of the visual programming environments such as dot Net used to create windows applications are more powerful to its corresponding Web-based tools. Fortunately, Visual Studio 2010 allows developers to create userinterfaces a window application, and, in a further step, to transform with a few instructions to a Web-based one. All that is needed is to build the windows control library, take the resulting dynamic link library (dll) and place it in the root directory of your Web based application. Furthermore, the following line of code to the source of your Web page must be added:

$<$ object id="myName" classid = "http: WindowsControlLibrary1.dll\#WindowsControlLibrary1.UserControl1" height $=" 469 "$ width $=" 702 "><$ lobject $>$
The main circuit contains all required elements and instruments. One important component which plays a central role in designing computer-controlled labs is the switching matrix, which is made as a grid of lines structured in the form of horizontal and vertical axes. At every crossing point where two lines are meeting, there is a switch which can be connected by a controlling PC command. The experimental circuit will be presented to the student as a live video stream containing all necessary components and instruments for enabling him to operate on his experiment interactively. On the circuit board, ten red light emitter diodes are placed that are located at the terminals of each component and instrument to be wired.

The red light of these LEDs will be passed by an HSL filter [42] which is implemented in forms of a software program. Hue indicates the color that is equal to the ratio of each primary (RGB) color which can be red, yellow, green, cyan, blue, magenta etc, and is referenced by an angle in the interval [0-360] on a color wheel. Saturation (S) indicates the quantity of intense or gray in the color, and takes a value from 0-1. Luminance (L) indicates the amount of light of the color. Luminance takes a value from $0-1$, where at 0 , In the HSL model, a color with maximum luminance $(\mathrm{L}=1)$ is always white, regardless of what the hue or saturation components are.

The filtered image helps to determine the positions of node's components and instruments on the captured video photo transmitted to the client. Any component or instrument belonging to the experiment kit must have LEDs at its connectable terminals (see Figure 4). Each component of the HSL color model is independent of the others. The hue should never change as their brightness changes. Hue, saturation and luminance is a very good and 


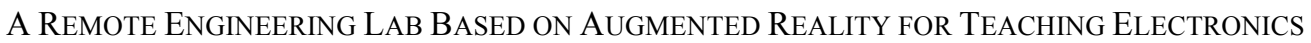

quickly mode to approach the desired color. The HSL filter is used when the target object is appreciably differing in color from the rest of the surroundings [43], then compares the resulted hue value with a pre-defined hue value, which in our case equals the red emitted LEDs' light. The circuit experiment along with the used instruments such as voltmeters and ammeters are presented using real-time video, as shown in Figure 4, leading to the fact that students deals with (actual) reality instead of interacting with virtual presentations.

Thereby, a student can wire his circuit by clicking on the button "wiring". Electrical connections between nodes in the real experimental setup are achieved through virtually connecting the corresponding nodes on the circuit board of the real-time video.

\section{COMPARATIVE EVALUATION}

It is of great significance to find out how much the implementation of augmented reality in our remote lab helps students understanding and strengthening their theoretical concepts. In order to achieve this, the remote AR lab was compared with an equivalent hand-on and virtual labs. Thereby, a survey questionnaire of closed end questions was used. Table I shows the survey items (evaluation criteria) along with the results achieved, indicating that the AR lab is generally well accepted from the students. The criteria result of the compared labs

The results show that the AR lab compared with its virtual equivalence is superior regarding the evaluation criteria "easy to use", "easy to understand the concept theory", "flexible to use in relation to time and place", "safety environment and satisfying".

\section{CONCLUSION}

This contribution discusses how we can build augmented reality remote labs for engineering education through overlaying live video stream with additional virtual objects. This approach is aimed at bypassing problems of virtual labs that do not allow students to feel the reality of components and instruments used in an engineering experiment. Through the comparative evaluation executed and our own experience with the remote AR lab, we are now capable of summarizing our major contributions. On the one hand, presenting real-time video of the instruments

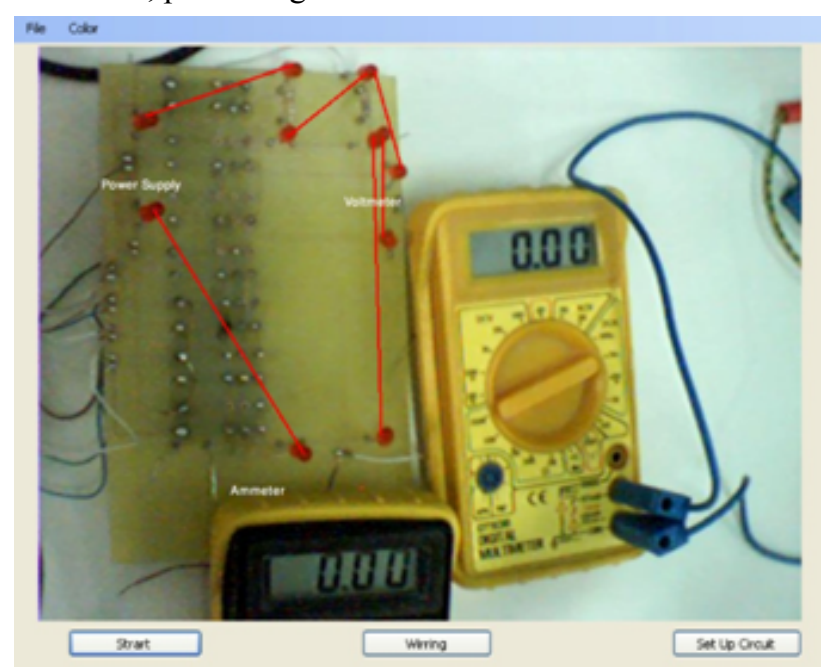

Figure 4. A virtually wired circuit experiment presented on the client user-interface as a real-time video
TABLE I.

\begin{tabular}{|l|l|c|c|c|}
\hline$\#$ & \multicolumn{1}{|c|}{ Survey item } & $\begin{array}{c}\text { Hand- } \\
\text { on lab }\end{array}$ & $\begin{array}{c}\text { Virtual } \\
\text { lab }\end{array}$ & AR lab \\
\hline 1 & Easy to use & $72 \%$ & $68 \%$ & $86 \%$ \\
\hline 2 & Easy to understand the concept theory & $80 \%$ & $76 \%$ & $78 \%$ \\
\hline 3 & Available for enough time & $44 \%$ & $82 \%$ & $84 \%$ \\
\hline 4 & Satisfying the knowledge theory & $80 \%$ & $68 \%$ & $80 \%$ \\
\hline 5 & Safe environmental for student. & $52 \%$ & $90 \%$ & $90 \%$ \\
\hline 6 & Progress new skills & $76 \%$ & $74 \%$ & $80 \%$ \\
\hline 7 & Teamwork's lab. is encouraged & $76 \%$ & $50 \%$ & $56 \%$ \\
\hline 8 & Comfortable physical place & $66 \%$ & $82 \%$ & $86 \%$ \\
\hline
\end{tabular}

and equipment of an experiment, students can move seamlessly from augmented video representations of test equipment in a remote lab environment to actual test equipment in a real lab and thus are capable of using this equipment competently as a direct result of their online experiences [44]. That is, offering a real view of experiment's components and instruments relieves the students in distinguishing the instruments used in a hand-on lab through the transferred live video stream of that experiment carried out. On the other, the invented remote AR lab helps the students in such a way that they not only can easily use it, but also enable them to better understand the concept theory as well. Finally, an e-instructor implemented as a subsystem in forms of a software program, prevents making any mistake connections by the students, and thus avoids the instruments to be damaged. As a result, using expensive and scarce instruments is no more a hindrance.

\section{REFERENCES}

[1] M. P. Clough, Using the laboratory to enhance student learning. In Learning Science and the Science of Learning, R.W. Bybee,Ed. Nationalsience Teacher Association, Washington,DC, pp. 85-97, 2002.

[2] G. Faucher, "The role of laboratories in engineering education," Int. J. Mechanical Eng. Education 13, pp. 195-198. 1985.

[3] http://www.abet.org/about-abet/

[4] S. Dormido, H.Vargas, J. Sánchez, N. Duro, R. Dormido, S. Dormido-Canto, F. Esquembre, "Using Web-Based Laboratories for Control Engineering Education," International Conference on Engineering Education, Coimbra, Portugal, September, 2007.

[5] Z. Nedic, J. Machotka, A. Nafalski, "Remote laboratories versus virtual and real laboratories," Proc. 33rd ASEE/IEEE Frontiers in Education Conference, Boulder, Colorado, USA, November, 2003.

[6] C. Colwell, E. Scanlon, M. Cooper, "Using remote laboratories to extend access to science and engineering. Comput. and Education $38, \quad 1-3, \quad 65-76.2002$. http://dx.doi.org/10.1016/S03601315(01)00077-X

[7] A. Papthanassiou, J. Oster, P. W. Baier, A novel simulation concept of reduced computational cost for TD-CDMA mobile radio systems with adaptive antennas. Proceedings of the vehicular technology conference 1999, Fall. Amesterdam, the Netherlands, pp. 218-222, 1999.

[8] C. A. Canizares, Z. T., "Advantages and disadvantages of using various computer tools in electrical engineering courses", IEEE Trans education 40,3, pp. 166-171, 1997 http://dx.doi.org/ $\underline{10.1109 / 13.618025}$

[9] D. J. Magin, S. Kanapathipillai, Engineering students' understanding of the role of experimentation. EurepianJ.Eng.Education25, 4, pp. 351-358, 2002. http://dx.doi.org/10.1080/03043790050200395

[10] G. Canfora, P. Daponte, S. Rapuano. Remotely accessible laboratory for electronic measurement teaching. Comut. Standards and interfaces 26, 6, pp. 489- 499, 2004. 


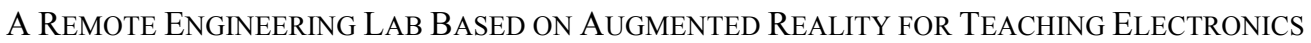

[11] W. G. Hutzel, A remotely accessed HVAC laboratory for distance education. Int. J. Eng. Education18, 6, pp. 711-716, 2002.

[12] J. Ma, J. Nickerson, Hands on, simulated and remote laboratories: A comparative literature review. ACM Computing Surveys, vol. 38, No.3, article 7, Sep. 2006.

[13] Z. Nedic, J. Machotka, A. Nafalski, "Remote Laboratory NetLab for Effective Interaction with Real Equipment over the Internet," Proc. 2008 IEEE Conference on Human Systems Interaction (HSI), Krakow, Poland, pp.846-851, May, 2008. http://dx.doi.org/10.1109/HSI.2008.4581553

[14] L. D. Feise, A. J. Rosa, "The Role of the Laboratory in Undergraduate Engineering Education," Journal of Engineering Education, Vol. 94, pp. 121-130, January, 2005. http://dx.doi.org/10.1002/j.2168-9830.2005.tb00833.x

[15] J. Y. Ma, J. S. Choi, "The Virtuality and Reality of Augmented Reality," Journal of Multimedia, Vol. 2, No.1, pp.32-37, February, 2007. http://dx.doi.org/10.4304/jmm.2.1.32-37

[16] P. Milgram, F. Kishino, "A Taxonomy of Mixed Reality Visual Displays," IEICE Transactions on Information Systems, vol. E77D,no.12, 1994.

[17] K. Zinser, "Integrated multimedia and visualization techniques for process S\&C, Proc," IEEE International Conference on Systems, Man and Cybernetics, Le Touquet, France, pp. 367-372, 1993. http://dx.doi.org/10.1109/ICSMC.1993.384772

[18] F. P. Vidal, F. Bello, K. W. Brodlie, N. W. John, D. Gould, R. Phillips, N. J. Avis, "Principles and applications of computer graphics in medicine," Computer Graphics Forum, Vol. 25, Issue 1 , pp. 113-137, 2006. http://dx.doi.org/10.1111/j.1467 8659.2006.00822.x

[19] J. Juhnke, T. Mills, J. Hoppenrath, "Designing for augmented cognition - problem solving for complex environments," Foundations of Augmented Cognition, Berlin: Springer-Verlag, pp. 424433, 2007. http://dx.doi.org/10.1007/978-3-540-73216-7_49

[20] C. E. Hughes, C. B. Stapleton, D. E. Hughes, E. M. Smith: "Mixed Reality in Education, Entertainment, and Training," IEEE Computer Graphics \& Applications, Vol. 25 Issue 6, pp. 24-30, 2005. http://dx.doi.org/10.1109/MCG.2005.139

[21] N. Navab, "Developing killer apps for industrial augmented reality," IEEE Computer Graphics \& Applications, Vol. 24 Issue 3, pp. 16-20, 2004. http://dx.doi.org/10.1109/MCG.2004.1297006

[22] H. WU: "Virtual Reality - Improving the Fidelity of Architectural visualization", Thesis in architecture, Master of scoence, Texas Tech University, may 2006.

[23] T. Nilsen, S. Linton, and J. Looser: " Motivations for Augmented Reality Gaming", Proceeding of Fuse '04, New Zealan Game Developer Conferences, pp. 86-93, 2004.

[24] B. Takacs: "Cognitive, Mental and Physical Rehabilitation Using a Configurable Virtual Reality System", The International Journal of Virtual RealityVol.5 ,PP 1-12, 2006.

[25] C. E. Hughes, C. B. Stapleton, D. E. Hughes, and E. M. Smith: "Mixed Reality in Education, Entertainment, and Training", IEEE Computer Graphics \& Applications, Vol. 25 Issue 6, pp. 24-30, 2005. http://dx.doi.org/10.1109/MCG.2005.139

[26] N. Navab: "Developing killer apps for industrial augmented reality", IEEE Computer Graphics \& Applications,Vol. 24 Issue 3, pp. 16-20,2004. http://dx.doi.org/10.1109/MCG.2004.1297006

[27] P.1 Milgram, and F. Kishino: "A Taxonomy of Mixed Reality Visual Displays", IEICE Transactions on Information Systems, vol. E77-D,no.12, 1994.

[28] W. T. Freeman, D. B. Anderson, P. A. Beardsley, C. N. Dodge, M. Roth, C. D. Weissman, W. S. Yerazunis, H. Kage, K. Kyuma, Y. Miyake, and K. Tanaka: "Computer Vision for Interactive Computer Graphics", IEEE Computer Graphics and Applications, vol. 18, No. 3, pp. 42-53, May 1998. http://dx.doi.org/10.1109/ $\underline{38.674971}$

[29] LearnFrame, "Facts, Figures and Forces Behind e-Learning," www.learnframe.com, New York, pp 4-81, 2000.

[30] HEEPF deliverables: "E-learning and simulation labs," http://www.heepf.org.eg.
[31] A. Aleksandrova, N. Nancheva, "Electromagnetism-Interaction of Simulation and Real Lab Experiment," Information Technologies and Knowledge, Vol. 1, 2007.

[32] ASTD/NGA, "A Vision of E-Learning for America's Workforce". Report on the Commission on Technology and Adult learning, 2001, www.nga.org/cda/files/elearningreport.pdf.

[33] S. Naidu, "E-Learning: A Guidebook of Principles, Procedures and Practices," 2nd edition, CEMCA, 2006.

[34] D. Huffaker, "The e-Learning Design Challenge: Technology, Models and Design Principles. Washington DC: American Society for Training \& Development (ASTD), 2004.

[35] J. Rosa, L. D. Feisel: "The Role of the Laboratory in Undergraduate Engineering Education," Journal of Engineering Education, 94(1), pp.121-130, January 2005.

[36] S. Das, L. Sharma, A. Gogoi: "Remote Communication Engineering Experiments through Internet," iJOE International Journal on Online Engineering, 2006.

[37] J. Ma, J. Nickerson, "Hands-On, Simulated, and Remote Laboratories: A Comparative Literature Review," ACM Computer Survey, Vol. 38, Issue 3, No.7, 2006.

[38] N. A. Streitz, "Cognitive compatibility as a central issue in human-computer interaction: Theoretical framework and empirical findings," Cognitive engineering in the design of human-computer interaction and expert systems, in G. Salvendy (Ed.), Amsterdam: Elsevier, pp. 75-82, 1987.

[39] B. Shneiderman, C. Plaisant, M. Cohen, Jacobs, Designing the User Interface: Strategies for Effective Human-Computer Interaction. Pearson-Addison Wesley Longman, 2010.

[40] F. Hayes-Roth, "Rule-based systems," Communications of the ACM, vol. 28, Nr. 9, pp. 921-932, 1985. http://dx.doi.org/10.1145/ $\underline{4284.4286}$

[41] I. Sommerville, Software Engineering (9th Edition). Addison Wesley, 2011.

[42] Z. Li, M. S. Drew, Fundamentals of Multimedia, PrenticeHall, (2004.

[43] L. Mornailla, T. G. Pekar, C. G. Solymosi, Z. Vamossy, "Mobile Robot Navigation Using Omnidirectional Vision," Proceedings of the 3rd Irish Machine Vision and Image Processing Conference (IMVIP'99), Dublin, Ireland, 1999.

[44] M. J. Callaghan, J. Harkin, T. M. McGinnity, L. P. Maguire, "Client-server architecture for remote experimentation for embedded systems," International Journal of Online Engineering (iJOE), 2006, 2(4).

\section{AUTHORS}

Salaheddin Odeh is with the Department of Computer Engineering, Faculty of Engineering, Al-Quds University, Abu Dies, Jerusalem, Palestine (sodeh@eng.alquds.edu).

Shatha Abu Shanab is with the College of Engineering and Technology, Palestine Technical UniversityKadoori, Tulkarm, Palestine (s.hodrob@ptuk.edu.ps).

Mahasen Anabtawi is with the Department of Computer Engineering, Faculty of Engineering, A1-Quds University, Abu Dies, Jerusalem, Palestine (manabtawi@eng.alquds.edu).

Rami Hodrob is with the Department of Computer and Information Technology, Faculty of Engineering and Information Technology, Arab American University, Jenin, Palestine (rhodrob@aauj.edu).

This paper presents an extended version of a paper entitled as "Remote Augmented Reality Engineering Labs" which was presented at IEEE EDUCON 2012 conference, Marrakesh, Morocco, April 2012. Received 28 January 2013. Published as resubmitted by the authors 27 May 2013. 